\title{
Elevated cord blood oxidative stress biomarkers negatively affect neonatal outcomes of mothers with severe preeclampsia: A case-control study
}

linli liu ( $\square$ liulinlisy9@163.com )

Fuzhou First Hospital

\section{Beihong Zheng}

FuJian Privincial Maternity and Children's Hospital

\section{ZhongQing Jiang}

Fuzhou First Hospital

\section{SanShan Wu}

Fuzhou First Hospital

Qiong Jin

Fuzhou First Hospital

PeiHong Lin

Fuzhou First Hospital

Zhou Lin

Fuzhou First Hospital

\section{Research article}

Keywords: severe preeclampsia, homocysteine, malondialdehyde, reactive oxygen species, oxidative stress, neonatal outcome

Posted Date: April 22nd, 2020

DOl: https://doi.org/10.21203/rs.3.rs-23080/v1

License: (c) (i) This work is licensed under a Creative Commons Attribution 4.0 International License. Read Full License 


\section{Abstract \\ Background}

To determine the relationship between the levels of stress biomarkers in cord blood and preeclampsia in a hospital-based population of pregnant patients, and to evaluate the resulting effects on pregnancy outcomes.

\section{Measures:}

This prospective case-control study included a total of 282 severe preeclamptic and 534 normal pregnant women. Fetal blood was collected from the umbilical cord at delivery and was utilized for Malonaldehyde (MDA), reactive oxygen species (ROS, superoxide dismutase (SOD) and homocysteine (Hcy) analysis. For a better assessment, we performed a univariate general linear regression model to control for potential confounders and determined the underlying influencing factors for high MDA and ROS. Moreover, a receiver operating characteristic curve analysis was conducted to determine the cutoff values for identifying severe preeclampsia. Further, the severe PE group was divided into the low or high MDA and low or high ROS subgroups according to their cut-off values. Finally, we created logistic regression models to estimate the adjusted odds ratio for each perinatal outcome in high-MDA and -ROS subgroup.

\section{Results}

MDA and ROS levels are higher in women with severe preeclampsia than in normotensive pregnant patients. However, when adjusted for cord blood Hcy levels, the difference is insignificant. Additionally, both MDA $(r=0.359, p<0.001)$ and ROS $(r=0.473, p<0.001)$ are positively correlated with cord blood Hcy level. The AUCs of MDA and ROS levels were 0.65 (95\% Cl: $0.60-0.69)$ and 0.88 (95\% Cl: 0.86-0.90), respectively, for predicting severe PE. Higher MDA and ROS levels are associated with increased risks of low Apgar score, admission to the NICU, and assisted ventilation for the newborn.

\section{Conclusion}

Increased levels of cord blood oxidative stress markers are significantly associated with negative effects on newborns. High cord blood Hcy levels might be involved in the observed elevated MDA and ROS concentrations in women with severe PE.

\section{Introduction}

Preeclampsia (PE) is a leading pregnancy complication that adversely affects maternal, fetal, and neonatal health [1]. Although the pathogenesis of this disease remains to be elucidated, generalized endothelial dysfunction accounting for impaired placenta function is known to play a role in PE [2], and is 
characterized by abnormal placentation and reduced placental perfusion [3]. Evidence suggests that poor trophoblast invasion of the spiral arteries during the placentation process [4] leads to a failure to transform the placental bed arteries from high resistance to low resistance vessels. This results in local ischemia, reperfusion damage, and oxidative stress (OS) [5]. Several hypotheses relate the cellular process of oxidative stress to endothelial dysfunction in PE [6]. The presence of hypoxia leads to oxidative stress due to an imbalance between increased reactive oxygen species (ROS) formation and defects in antioxidant defence mechanisms, thereby causing damage to the placenta [7]. Impaired placenta function can lead to preeclampsia and foetal growth restriction secondary to hypoxia [8].

Previous clinical studies have determined maternal and foetal serum homocysteine (Hcy) levels to be significantly higher in patients with severe preeclampsia compared to control groups [9]. These findings suggest that high serum Hcy may be an independent predictor of severe preeclampsia during pregnancy. Recent evidence suggests that increased Hcy levels lead to cellular oxidative stress, stimulate reactive oxygen species (ROS) production, and cause generalized endothelial dysfunction, which are common risk factors for PE [10]. Excessive oxidative stress products may play a role in contributing to worsened neonatal outcomes [11]. Though there are numerous reports on maternal oxidative stress in the context of preeclampsia, comprehensive studies evaluating malonaldehyde (MDA), superoxide dismutase (SOD), and ROS levels and their correlation with neonatal outcomes are fewer.

The purpose of our study is to determine the relationship between foetal cord blood Hcy, MDA, SOD, and ROS and PE in a hospital-based population, and to investigate whether the association between cord blood MDA and ROS and PE is influenced by cord blood homocysteine levels. Furthermore, this study evaluates the impact of higher MDA and ROS levels on perinatal outcomes.

\section{Materials And Methods}

\section{Study Population Sample}

This is an observational, prospective case-control study. Eight hundred and sixteen singleton pregnant women who were treated at the Affiliated Fuzhou First Hospital of Fujian Medical University between November 2017 and November 2019 were included in this study. Of the participants, 282 were diagnosed with severe PE and 534 were diagnosed as having a normotensive pregnancy. A diagnosis of severe PE was based on one or more of the following criteria: systolic blood pressure $\geq 160 \mathrm{mmHg}$ or diastolic blood pressure $\geq 110 \mathrm{mmHg}$ on two occasions separated by at least 6 hours after 20 weeks gestation; proteinuria $\geq 5 \mathrm{~g}$ in 24 hours or $\geq 3 \mathrm{~g}$ on dipstick; oliguria ( $\leq 500 \mathrm{~mL}$ in 24 hours); cerebral or visual disturbances; epigastric pain; thrombocytopenia; increased liver enzyme serum levels; pulmonary oedema or cyanosis; uteroplacental dysfunction; foetal growth restriction; and eclampsia [1, 12]. Each patient routinely received folic acid supplementation during the first trimester of her pregnancy. No patient had a history of pre-existing hypertension, mild preeclampsia, gestational hypertension, gestational diabetes, type 1 or type 2 diabetes mellitus, seizure disorders, renal or liver diseases, infectious diseases, treatment with antifolate drugs (such as antiepileptics or methotrexate), pregnancy with thyroid dysfunction, or intrahepatic cholestasis of pregnancy. Each participant provided informed consent after receiving a 
detailed description of the research purpose prior to study enrolment. This study was approved by the Ethics Committee of Affiliated Fuzhou First Hospital of Fujian Medical University and conducted in accordance with the Declaration of Helsinki.

Our obstetrics department provided complete prenatal care to each patient. Demographics, obstetric history, perinatal data, delivery, and newborn outcomes were recorded by two trained research obstetricians from Fuzhou Maternal And Child Health Care System. Maternal serum Hcy levels at the first trimester (the first prenatal appointment between 8-12 weeks), the second trimester (24-28 weeks), and the third trimester (admission to the hospital for delivery) were recorded.

\section{Cord Blood Sample Collection and Markers Measurement}

Umbilical cord blood samples were obtained by clamping the umbilical vein immediately after delivery and drawing blood into ethylene diamine tetraacetic acid tubes. All specimens were directly processed within two hours for MDA, ROS, SOD, and Hcy analysis, which were detected by thiobarbituric acid reaction, xanthinoxidase method, luminol-enhanced chemiluminescence, and enzyme linked immunosorbent assay, respectively, with commercially available kits according to the manufacturer's instructions. Lab staff was blind to the identity of the sample.

\section{Statistical Analyses}

We analysed the data distribution using the Kolmogorov-Smirnov and Shapiro Wilk tests. Continuous variables were expressed as mean \pm standard deviation (SD) or median (interquartile range), as appropriate, and were compared using Student's t-test or the Mann-Whitney U test. Categorical data were expressed as numbers (per cent), and compared using the $\chi 2$ test or Fisher's exact test. We calculated mean differences in the levels of MDA, SOD, and ROS based on the univariate general linear regression model with adjustment for confounding factors. Pearson correlation analysis was conducted to determine the correlations between cord blood Hcy levels and MDA and ROS levels. The optimal cut-off values for predicting severe PE were obtained using ROC curve analysis. Each optimal cut-off point was assessed via searching for the maximum value of the Youden index.

Moreover, adjusted linear regression or logistic regression analyses were used to explore newborn outcomes among different MDA and ROS level groups to control for certain confounders. Effects were described as odds ratio (OR) for logistic regressions and unstandardized regression coefficient (B) for linear regressions, both with $95 \%$ confidence intervals (Cls). All statistical analyses were conducted using the statistical software SPSS version 19.0 (SPSS, Inc.; Chicago, IL, USA). All of the tests were two-sided and statistical significance was set at $P<0.05$.

\section{Results}

\section{Background Characteristics of the Study Population}

The patients' clinical and demographic characteristics are presented in Table 1. Maternal age and prepregnancy body mass index (BMI) are similar between the two groups. The mean diastolic blood pressures 
(PE group, $161.03 \mathrm{mmHg}$; normotensive group, $105.12 \mathrm{mmHg} ; P<0.001)$ and systolic blood pressures (PE group, $100.71 \mathrm{mmHg}$; normotensive group, $80.46 \mathrm{mmHg} ; \mathrm{P}<0.001)$ are significantly greater in the severe $\mathrm{PE}$ than in the control subjects (data not shown). Proteinuria is detected only in patients with severe PE. However, the total cholesterol (TC) and haemoglobin (HB) in patients with severe PE are lower than in normotensive patients. The incidence of placental abruption is higher in patients with severe PE than in normal pregnancies $(3.19 \%$ vs. $0.37 \% ; P=0.003)$. Patients with severe $\mathrm{PE}$ have significantly elevated Hcy concentration in the first, second, and third trimesters of pregnancy, and in the umbilical cord blood. Newborns of patients with severe PE have significantly higher incidence rates of premature birth $(<37$ weeks) and low 5-minute Apgar scores ( $<8)$, higher NICU admission rates, higher rates of assisted ventilation, and lower birth weights $(P<0.001)$.

\section{Higher Cord Blood MDA and ROS levels in severe PE women}

Compared with the control group, patients with severe PE exhibited higher MDA (1.17, 95\% Cl: 1.09-1.11) and ROS levels (2.94, 95\% Cl: 2.58-3.30). And after adjustment for maternal characteristics (age, BMI, gravidity, parity, and Hcy levels in the first and second trimesters), pregnancy complications (placenta praevia, placental abruption, and PROM), maternal metabolic indicators (TC, HDL, LDL, and HB), and foetal factors (gestational age, sex, birth weight, mode of delivery, anodyne labour, labour time, and postpartum haemorrhage), this result was still consistently observed in the two groups

(Model 1). When the data is adjusted for Hcy level at the time of admission, the difference in MDA (1.06, $95 \%$ Cl: 0.64 to 1.73) disappeared between the two groups(Model 2). The differences remained insignificant after additional adjustment for cord blood Hcy levels (MDA = 1.03, 95\% Cl: 0.89-1.87; ROS = $1.85,95 \% \mathrm{Cl}: 0.73$ to 2.44 ) (Table 2) (Model 3). SOD levels are lower in patients with severe PE compared to normotensive patients, but the difference is not statistically significant.

In addition, linear correlation analysis indicates a strong positive correlation of cord blood Hcy levels with MDA ( $r=0.359, P<0.001$; Fig. 1a) and ROS levels $(r=0.473, P<0.001$; Fig. 1b). The cord blood Hcy levels are significantly correlated with the maternal levels in the third trimester $(r=0.78 ; P<0.001)$.

\section{Higher Cord Blood MDA and ROS levels are Associated with Worse Outcomes}

Subsequently, using cut-off values of $6.67 \mu \mathrm{mol} / \mathrm{L}$ and $4.59 \mu \mathrm{mol} / \mathrm{L}, \mathrm{MDA}$ and ROS predict severe PE with a sensitivity of $39 \%$ and $90.3 \%$, and a specificity of $93.6 \%$ and $63.7 \%$, respectively (ROC areas under curve: $0.65,95 \% \mathrm{Cl}: 0.60-0.69, \mathrm{P}<0.001$; and $0.88,95 \% \mathrm{Cl}: 0.86-0.90, \mathrm{P}<0.001 ;$ Fig. 2 ). To further investigate whether high MDA and ROS levels cause adverse neonatal outcomes, we divided the patients in the severe PE groups according to levels of oxidative stress biomarkers: low MDA $(<6.67 \mu \mathrm{mol} / \mathrm{L}, \mathrm{n}=174)$ or high $\operatorname{MDA}(\geq 6.67 \mu \mathrm{mol} / \mathrm{L}, \mathrm{n}=108)$, and low ROS ( $4.95 \mu \mathrm{mol} / \mathrm{L}, \mathrm{n}=43)$ or high ROS ( $\geq 4.95 \mu \mathrm{mol} / \mathrm{L}, \mathrm{n}=239)$. We adjusted for maternal characteristics (age, BMI, gravidity, parity, and Hcy levels in pregnancy), pregnancy complications (placenta praevia, placental abruption, and PROM), maternal metabolic indicators (TC, HDL, LDL, and HB), and cord blood Hcy level. The adjusted odds of having a low Apgar 
score (<8) is greater for patients with high MDA (1.25, 95\% Cl: 1.02-2.03) and high ROS (1.69, 95\% Cl: 1.21 to 2.63). Finally, infants born to patients with high MDA and high ROS show greater risk of admission to the NICU and requirement of assisted ventilation than infants born to patients with low MDA and low ROS (Tables 3 and 4).

\section{Discussion}

This study demonstrates that severe PE significantly increases MDA and ROS levels in cord blood. Even more importantly, this is the first study to report a correlation between increased MDA and ROS blood levels and neonatal outcomes in mothers with severe PE.

Elevated levels of circulating Hcy have been considered to be a risk factor for endothelial dysfunction and preeclampsia [13], and endothelial cell activation or dysfunction are the most popular hypothetic factors in the etiopathogenesis of preeclampsia [6]. Consequently, it has been suggested that hyperhomocysteinaemia during pregnancy may contribute to the occurrence of preeclampsia. In this study, we found that maternal Hcy levels during pregnancy and cord blood Hcy levels are significantly higher in patients with severe PE compared to levels found in normotensive patients. We also found a correlation between maternal and cord blood Hcy levels, with the latter levels being significantly lower. Our results align with those of several previous studies [14]. In past studies, we found that maternal serum Hcy levels are maintained within the normal range in normotensive women during pregnancy, and that Hcy levels decline as the pregnancy progresses. On the contrary, serum Hcy levels increase with the degree of disease and the gestational age of pregnancy in patients with severe PE (data not published). Therefore, high serum Hcy is an independent predictor of severe preeclampsia during pregnancy.

We also found higher levels of TC and a higher ratio of placental abruption in patients with severe PE compared to normotensive patients. In addition, while maternal age and BMI are reported to be risk factors of $P E$, there is no significant difference between the two groups for these parameters. Maternal age and $\mathrm{BMI}$, as well as other known risk factors, were accounted for using multiple logistic regression to eliminate confounding factors.

Preeclampsia is linked to impaired endothelial function, which originates from production of inflammatory and cytotoxic factors by ischemic placenta [15], and results in systemic oxidative stress (OS) [16]. The increased products of oxidative stress, which have been reported in several meta-analyses, may be an underlying mechanism for endothelial dysfunction in preeclampsia. Previous studies detected increased oxidative stress in plasma and placental tissue in mothers with PE [17]. Increased oxidative stress in patients with PE might induce ROS and xanthine oxidase activity. The hypothesis that free radical generation contributes to endothelial dysfunction in PE is supported by studies showing an increase in lipid peroxidation and a decrease in antioxidant patterns in patients with PE [18]. In this study, we found that cord blood levels of the most widely used markers of secondary end products of lipid peroxidation (such us MDA) and ROS are significantly increased in patients with severe PE. However, when data was adjusted for cord blood Hcy levels, there was no significant difference in MDA and ROS levels between patients with severe PE and normotensive patients. This indicates that cord blood Hcy levels may influence the 
production of MDA and ROS in patients with severe PE. Other studies have reported significant increases in oxidative stress, measured as MDA and ROS, in women with PE [19]. On the contrary, some studies did not find evidence of significantly elevated markers of oxidative stress in patients with PE [20]. These differences may be due to variations in study designs and sample sizes.

Previous reports have found a positive correlation between MDA levels and blood pressure [21]. Another study has reported MDA levels to be significantly different between women with either mild or severe preeclampsia and healthy pregnant women [22]. Increased MDA levels may be an indicator of cellular damage [23], as it is widely reported that insufficient antioxidant defence systems, marked by increased MDA levels, plays a role in the pathogenesis of preeclampsia [8]. Another marker of oxidative stress, ROS, was also found to be significantly increased in preeclamptic placental tissue [24] and neonatal cord blood [25] when compared to levels found in normal pregnancies. ROS has been reported to cause smooth muscles contraction and directly inactivate nitric oxide, an endothelium derived relaxing factor, thereby affecting vasculartone. Thus, increased levels of MDA and ROS may play a synergistic role in endothelial and placental dysfunction, resulting in adverse pregnancy outcomes.

Few studies have described the influence of maternal or foetal oxidative stress on perinatal outcome [16]. We found that increased foetal oxidative stress biomarkers are strongly associated with adverse birth outcomes. As neonates do not have well-developed antioxidant defence mechanisms, they are more susceptible for oxidative stress injury. The combination of elevated MDA and decreased antioxidant capacity provides a clear indication of the presence of oxidative stress [26]. Briefly, pregnancy is a precisely coordinated dynamic process that involves systemic and local changes in the mother to support nutrient and oxygen supply to the baby for growth in utero [17]. However, increased oxidative stress may disrupt this process and compromise foetal growth and development [27], resulting in poor pregnancy outcomes [17]. In preeclampsia, ROS accumulation is uncontrolled [28], resulting in damage to maternal and fetal tissues. A previous cohort study reported a negative correlation between cord blood levels of oxidative stress markers, gestational age, and birth weight [29]. Notably, this study found no significant associations between neonatal oxidative stress markers and birth weight or gestational age, but increased oxidative stress markers were associated with low Apgar scores (<8), admission to the NICU, and assisted ventilation. This relationship may be due to placental ischemia, resulting in reduced oxygen supply, leading to neonatal asphyxia [30].

Our study is not without limitations. The study design led to the exclusion of several participants. This may have resulted in a selection bias, and our results may not be representative of the general population. Additionally, Hcy levels can be affected by multiple biochemical influences, such as folic acid and vitamin B12, which were not considered as confounding factors in this study. Prospective studies with large sample sizes that evaluate more confounding factors are needed to further investigate the relationship between Hcy, oxidative biomarkers, and foetal outcomes.

\section{Conclusion}


In summary, we found that elevated cord blood Hcy levels may be an underlying mechanism for the observed elevated cord blood oxidative stress in women with severe PE, and higher cord blood MDA and ROS are associated with low Apgar scores $(<8)$, admission to the NICU, and assisted ventilation of the newborn.

\section{Declarations}

\section{Compliance with ethical standard}

\section{Conflict of interest:}

The authors declare no conficts of interest.

\section{Funding:}

This study was funded by the grant from the Department of Science and Technology of Fuzhou City (grant 2018-S-105-4 and 2017-S-129-3), Clinical Medicine Center Construction Program of Fujian Province (grant 201610192), and the Natural Science Foundation of Fujian Province (grant 2019D004). Key Department of Gynecology Construction Program of Fujian Province.The authors gratefully acknowledge the contributions of the pregnant women and their children.

\section{Data Statement}

All data included in this study are available upon request by contact with the corresponding author.

\section{Authors' Contributions:}

LL-L conceived and designed the study. Z-L and BH-Z analysed the data. ZQ-J, LL-W, Q-J, PH-Land SS-W coordinated data collection. The first draft of the paper was written by LL-L. All authors contributed to the interpretation of the results and approved the final version of the manuscript.

\section{Acknowledgements:}

We appreciate the immense support from the midwives during sample collection. The authors would also like to thank researcher Huang Meng, for his help in statistical analysis.

\section{References}

1. Mol BWJ, Roberts CT, Thangaratinam S, Magee LA, de Groot CJM, Hofmeyr GJ (2016)Pre-eclampsia, Lancet (London, England) 387(10022) : 999-1011. https://doi:10.1016/s0140-6736(15)00070-7. 
2. Mannaerts D, Faes E, Gielis J, Van Craenenbroeck E, Cos P, Spaanderman M, Gyselaers W, Cornette J, Jacquemyn Y (2018) Oxidative stress and endothelial function in normal pregnancy versus preeclampsia, a combined longitudinal and case control study, BMC Pregnancy Childbirth 18(1) : 60. https://doi:10.1186/s12884-018-1685-5.

3. Brownfoot FC, Hannan NJ, Cannon P, Nguyen V, Hastie R, Parry LJ, Senadheera S, Tuohey L, Tong S, Kaitu'u-Lino TJ (2019) Sulfasalazine reduces placental secretion of antiangiogenic factors, upregulates the secretion of placental growth factor and rescues endothelial dysfunction, EBioMedicine 41:636-648. https:// doi:10.1016/j.ebiom.2019.02.013.

4. Aouache R, Biquard L,Vaiman D, Miralles F (2018) Oxidative Stress in Preeclampsia and Placental Diseases, Int J Mol Sci 19(5). https:// doi:10.3390/ijms19051496

5. Taysi S, Tascan AS, Ugur MG, Demir M (2019) Radicals Oxidative/Nitrosative Stress and Preeclampsia, Mini reviews in medicinal chemistry 19(3):178-193. https://doi:10.2174/1389557518666181015151350

6. Brosens I, Brosens JJ, Muter J, Puttemans P, Benagiano G (2019) Preeclampsia: the role of persistent endothelial cells in uteroplacental arteries, American journal of obstetrics and gynecology 221(3): 219226. https://doi:10.1016/j.ajog.2019.01.239

7. Schoots MH, Gordijn SJ, Scherjon SA, van Goor H, Hillebrands JL (2018) Oxidative stress in placental pathology, Placenta 69:153-161. https://doi:10.1016/j.placenta.2018.03.003

8. Taravati A, Tohidi F (2018) Comprehensive analysis of oxidative stress markers and antioxidants status in preeclampsia, Taiwanese Journal of Obstetrics and Gynecology 57(6):779-790. https://doi:10.1016/j.tjog.2018.10.002

9. Pisal H, Dangat K, Randhir K, Khaire A, Mehendale S, Joshi S (2019) Higher maternal plasma folate, vitamin B12 and homocysteine levels in women with preeclampsia, J Hum Hypertens 33(5):393-399. https://doi:10.1038/s41371-019-0164-4

10. Lu ZH, Li J, Li XL, Ding M, Mao CJ, Zhu XY, Liu CF (2019) Hypertension with Hyperhomocysteinemia Increases the Risk of Early Cognitive Impairment after First-Ever Ischemic Stroke, European neurology 1-11. https://doi:10.1159/000504704

11. Odame Anto E, Owiredu W, Sakyi SA, Turpin CA, Ephraim RKD, Fondjo LA, Obirikorang C, Adua E, Acheampong $E$ (2018) Adverse pregnancy outcomes and imbalance in angiogenic growth mediators and oxidative stress biomarkers is associated with advanced maternal age births: A prospective cohort study in Ghana, PloS one 13(7) :581-586. https://doi:10.1371/journal.pone.0200581

12. Phipps EA, Thadhani R, Benzing T, Karumanchi SA (2019) Pre-eclampsia: pathogenesis, novel diagnostics and therapies, Nature reviews. Nephrology 15(5) :275-289. https://doi:10.1038/s41581019-0119-6

13. Wu F, Yang H, Liu B (2019) Association between Homocysteine and Arterial Stiffness in Women with a History of Preeclampsia, Journal of vascular research 56(3): 152-159. https://doi:10.1159/000500358

14. Wang J, Trudinger BJ, Duarte N, Wilchen DE, Wang XL (2000) Elevated circulating homocyst(e)ine levels in placental vascular disease and associated pre-eclampsia, BJOG : an international journal of obstetrics and gynaecology 107(7): 935-938. https://doi:10.1111/j.1471-0528.2000.tb11095.x 
15. Small HY, Currie GE, Delles C (2016) Prostasin, proteases, and preeclampsia, Journal of hypertension 34(2): 193-195. https://doi:10.1097/hjh.0000000000000828

16. Bharadwaj S, Bhat VB, Vickneswaran V, Adhisivam B, Zachariah B, Habeebullah S (2018) Oxidative stress in preeclamptic mother - newborn dyads and its correlation with early neonatal outcome - a case control study, The journal of maternal-fetal \& neonatal medicine : the official journal of the European Association of Perinatal Medicine, the Federation of Asia and Oceania Perinatal Societies, the International Society of Perinatal Obstetricians 31(12):1548-1553.

https://doi:10.1080/14767058.2017.1319933

17. Kao CK, Morton JS, Quon AL, Reyes LM, Lopez-Jaramillo P, avidge STD (2016) Mechanism of vascular dysfunction due to circulating factors in women with pre-eclampsia, Clinical science (London, England : 1979) 130(7): 539-549. https://doi:10.1042/cs20150678

18. Shah DA, Khalil RA (2015) Bioactive factors in uteroplacental and systemic circulation link placental ischemia to generalized vascular dysfunction in hypertensive pregnancy and preeclampsia, Biochemical pharmacology 95(4): 211-226. https://doi:10.1016/j.bcp.2015.04.012

19. Ferguson KK, Meeker JD, McElrath TF, Mukherjee B, Cantonwine DE (2017) Repeated measures of inflammation and oxidative stress biomarkers in preeclamptic and normotensive pregnancies, American journal of obstetrics and gynecology 216(5): 527.e1-527.e9.

https://doi:10.1016/j.ajog.2016.12.174

20. Diedrich F, Renner A, Rath W, Kuhn W, Wieland E (2001) Lipid hydroperoxides and free radical scavenging enzyme activities in preeclampsia and HELLP (hemolysis, elevated liver enzymes, and low platelet count) syndrome: no evidence for circulating primary products of lipid peroxidation, American journal of obstetrics and gynecology 185(1): 166-172. https://doi:10.1067/mob.2001.115281

21. Kaur G, Mishra S, Sehgal A, Prasad R(2008) Alterations in lipid peroxidation and antioxidant status in pregnancy with preeclampsia, Molecular and cellular biochemistry 313: 37-44.

https://doi:10.1007/s11010-008-9739-z

22. Jain SK, Wise R (1995) Relationship between elevated lipid peroxides, vitamin E deficiency and hypertension in preeclampsia, Molecular and cellular biochemistry 151(1): 33-38. https://doi:10.1007/bf01076893

23. Walsh SW, Vaughan JE, Wang Y, Roberts LJ (2000) Placental isoprostane is significantly increased in preeclampsia, FASEB journal : official publication of the Federation of American Societies for Experimental Biology 14(10): 1289-1296. https://doi:10.1096/fj.14.10.1289

24. Puttabyatappa M, Banker M, Zeng L, Goodrich JM, Domino SE, Dolinoy DC, Meeker JD (2020) Maternal Exposure to Environmental Disruptors and Sexually Dimorphic Changes in Maternal and Neonatal Oxidative Stress, The Journal of clinical endocrinology and metabolism 105(2). https://doi:10.1210/clinem/dgz063

25. Veiga-Lopez A, Pennathur S, Kannan K, Patisaul HB, Dolinoy DC, Zeng L, Padmanabhan V (2015) Impact of gestational bisphenol A on oxidative stress and free fatty acids: Human association and interspecies animal testing studies, Endocrinology 156(3): 911-922. https://doi:10.1210/en.2014-1863 
26. Raijmakers MT, Dechend R, Poston L (2004) Oxidative stress and preeclampsia: rationale for antioxidant clinical trials, Hypertension (Dallas, Tex. : 1979) 44(4): 374-380.

https://doi:10.1161/01.hyp.0000141085.98320.0127.

27. Marseglia L, D'Angelo G, Granese R, Falsaperla R, Reiter RJ, Corsello G, Gitto E (2019) Role of oxidative stress in neonatal respiratory distress syndrome, Free radical biology \& medicine 142:132-137. https://doi:10.1016/j.freeradbiomed.2019.04.029

28. Wang YP, Walsh SW, Guo JD, Zhang JY(1991) Maternal levels of prostacyclin, thromboxane, vitamin E, and lipid peroxides throughout normal pregnancy, American journal of obstetrics and gynecology 165:1690-1694. https://doi:10.1016/0002-9378(91)90016-k

29. Menon R (2014) Oxidative stress damage as a detrimental factor in preterm birth pathology, Frontiers in immunology 5: 567-571. https://doi:10.3389/fimmu.2014.00567

30. Goldenberg RL, Harrison MS, McClure EM (2016) Stillbirths: The Hidden Birth Asphyxia - US and Global Perspectives, Clinics in perinatology 43(3): 439-453. https://doi:10.1016/j.clp.2016.04.004

\section{Tables}




\section{Table 1 Clinical characteristics of the population sample}

\begin{tabular}{|c|c|c|c|}
\hline \multirow[t]{2}{*}{ Characteristic } & \multirow{2}{*}{$\begin{array}{l}\text { severe PE } \\
n=282\end{array}$} & normotension & \multirow[t]{2}{*}{$\mathrm{P}$} \\
\hline & & $n=534$ & \\
\hline Age, yr & $29.01 \pm 14.77$ & $29.18 \pm 4.62$ & 0.627 \\
\hline Prepregnancy BMI,kg/m² & $23.53 \pm 2.43$ & $23.03 \pm 2.52$ & 0.144 \\
\hline Gravidity,N & $2(2,4)$ & $2(1,3)$ & 0.348 \\
\hline Parity,N & $2(1,3)$ & $2(1,2)$ & 0.857 \\
\hline \multicolumn{4}{|l|}{ Metabolic indicators at 3rd trimester } \\
\hline Total Cholesterol,mmol/L & $4.15(3.97,5.87)$ & $2.30(1.86,3.52)$ & $<0.001$ \\
\hline $\mathrm{HDL}-\mathrm{C}, \mu \mathrm{mmol} / \mathrm{L}$ & $1.53(1.22,2.03)$ & $1.87(0.9,1.96)$ & 0.466 \\
\hline LDL-C,mmol/L & $2.44(1.79,3.03)$ & $2.19(1.23,3.46)$ & 0.563 \\
\hline$H B, g / l$ & $93.67 \pm 11.39$ & $96.12 \pm 10.92$ & 0.003 \\
\hline Hcy level at 1 st trimester, $\mu \mathrm{mol} / \mathrm{l}$ & $8.92 \pm 2.72$ & $6.54 \pm 1.39$ & $<0.001$ \\
\hline Hcy level at 2nd trimester, $\mu \mathrm{mol} / \mathrm{I}$ & $10.39 \pm 3.12$ & $5.59 \pm 1.49$ & $<0.001$ \\
\hline Hcy level at 3rd trimester, $\mu \mathrm{mol} / \mathrm{I}$ & $16.31 \pm 4.74$ & $5.75 \pm 1.68$ & $<0.001$ \\
\hline Cord blood Hcy level, $\mu \mathrm{mol} / \mathrm{I}$ & $13.42 \pm 3.27$ & $5.82 \pm 1.65$ & $<0.001$ \\
\hline \multicolumn{4}{|l|}{ Complications of pregnancy } \\
\hline Placenta previa,N (\%) & $3(1.06)$ & $5(0.94)$ & 0.842 \\
\hline Placental abruption,N (\%) & $9(3.19)$ & $2(0.37)$ & 0.001 \\
\hline PROM, N (\%) & $74(26.24)$ & $117(21.91)$ & 0.165 \\
\hline \multicolumn{4}{|l|}{ Delivery data } \\
\hline Anodyne labor,N (\%) & $53(18.79)$ & 106(19.85) & 0.717 \\
\hline Labor time,hrs & $11.4 \pm 5.76$ & $10.62 \pm 4.67$ & 0.036 \\
\hline Premature birth (< 37 weeks) & 144(51.06) & $52(9.74)$ & $<0.001$ \\
\hline Gestational age at delivery, wk & $35.82 \pm 2.97$ & $38.79 \pm 1.70$ & $<0.001$ \\
\hline Birth weight,g & $2777.00 \pm 577.85$ & $3253.85 \pm 438.68$ & $<0.001$ \\
\hline Cesarean section,N (\%) & 107(37.94) & $228(42.70)$ & 0.189 \\
\hline Male,N (\%) & 151(53.55) & $315(56.00)$ & 0.962 \\
\hline Postpartum hemorrhage,ml & $362.16 \pm 37.84$ & $272.33 \pm 59.18$ & 0.798 \\
\hline
\end{tabular}




\section{Table 1 Clinical characteristics of the population sample}

\begin{tabular}{llll} 
Turbid amniotic fluid,N (\%) & $45(15.96)$ & $79(14.79)$ & 0.66 \\
\hline Apgar score < 8 at 5 min,N (\%) & $20(7.09)$ & $3(0.56)$ & $<0.001$ \\
\hline Admission to NICU, N (\%) & $38(13.48)$ & $4(0.75)$ & $<0.001$ \\
\hline Assisted ventilation,N (\%) & $24(8.51)$ & $3(0.56)$ & $<0.001$
\end{tabular}

Abbreviations:PE, preeclampsia; BMI, body mass index;Hcy,homocysteine;PROM, premature rupture of fetal membranes;

HDL-C, high-density lipoprotein-cholesterol;HB,Hemoglobin;NICU,neontatal intensive care unit;

Data are mean \pm standard deviation,number (percent) or median (interquartile rage). P values were calculated by independent

Student t-test,Mann-Whitney U,Chi-square test or Fisher's exact test.

Tabel 2 Cord blood oxidative stress products evaluation.

variables

Mean difference $(95 \% \mathrm{Cl})$

\begin{tabular}{|c|c|c|c|c|c|c|c|}
\hline & $\begin{array}{l}\text { Severe } \\
\mathrm{PE}\end{array}$ & control & \multirow[t]{2}{*}{$\mathrm{p}$} & \multirow[t]{2}{*}{ Unadjusted } & \multirow[t]{2}{*}{ Model 1} & \multirow[t]{2}{*}{ Model 2} & \multirow[t]{2}{*}{ Model 3} \\
\hline & $\mathrm{n}=282$ & $\mathrm{n}=534$ & & & & & \\
\hline $\mathrm{MDA}, \mu \mathrm{mol} / \mathrm{L}$ & $\begin{array}{l}5.90 \pm \\
1.41\end{array}$ & $\begin{array}{l}4.72 \pm \\
1.44\end{array}$ & $\begin{array}{l}< \\
0.001\end{array}$ & $\begin{array}{l}1.17(1.09 \\
\text { to } 1.44)\end{array}$ & $\begin{array}{l}1.12(1.07 \\
\text { to } 1.57)\end{array}$ & $\begin{array}{l}1.06(0.64 \\
\text { to } 1.73)\end{array}$ & $\begin{array}{l}1.03(0.89 \\
\text { to } 1.87)\end{array}$ \\
\hline $\mathrm{ROS}, \mu \mathrm{mol} / \mathrm{L}$ & $\begin{array}{l}7.44 \pm \\
2.21\end{array}$ & $\begin{array}{l}4.50 \pm \\
1.62\end{array}$ & $\begin{array}{l}< \\
0.001\end{array}$ & $\begin{array}{l}2.94(2.58 \\
\text { to } 3.30)\end{array}$ & $\begin{array}{l}2.79(2.16 \\
\text { to } 3.41)\end{array}$ & $\begin{array}{l}2.54(1.75 \\
\text { to } 3.32)\end{array}$ & $\begin{array}{l}1.85(0.73 \\
\text { to } 2.44)\end{array}$ \\
\hline $\mathrm{SOD}, \mathrm{U} / \mathrm{mL}$ & $\begin{array}{l}88.55 \\
\pm 25.01\end{array}$ & $\begin{array}{l}91.88 \\
\pm 12.89\end{array}$ & 0.112 & $\begin{array}{l}-1.62(-7.18 \\
\text { to } 3.95)\end{array}$ & $\begin{array}{l}-1.62 \\
(-7.18 \text { to } \\
3.95)\end{array}$ & $\begin{array}{l}-6.32 \\
(-17.05 \text { to } \\
4.41)\end{array}$ & $\begin{array}{l}-4.03 \\
(-12.26 \text { to } \\
4.20)\end{array}$ \\
\hline
\end{tabular}

Abbreviations: SOD,Superoxide dismutase;MDA,Malondialdehyde;ROS,Reactive Oxygen Species.Data are mean $\pm S D$, or mean difference ( $95 \%$ confidence interval).

Unadjusted: uncontrolled for any indicators.

Model 1: controlled for maternal characteristics (age, BMI, gravidity, parity, both Hcy level at 1 st and 2nd trimester), pregnancy complications (placenta previa, placental abruption, and PROM), maternal metabolic indicators (TC, HDL, LDL, HB), and fetal factors (gestational age, sex, birth weight, mode of delivery, anodyne labor, labor time, and postpartum hemorrhage).

Model 2: Model 1 plus Hcy level at the time of admission.

Model 3: Model 2 plus Hcy level in umbilical cord blood. 


\section{Tabel 3 Linear or binomial logistic regression models predicting effect of MDA concentration on birth outcomes before and after adjustment for}

confounding factors.values are linear regression coefficients or logistic regression odds ratios with $95 \%$ confidence intervals.

\begin{tabular}{|c|c|c|c|c|c|c|c|}
\hline \multirow[t]{2}{*}{ variables } & \multirow{2}{*}{$\begin{array}{l}\text { High } \\
\text { MDA } \\
n=108\end{array}$} & Low MDA & \multirow[b]{2}{*}{$p$} & \multicolumn{2}{|l|}{ Unadjusted } & \multicolumn{2}{|l|}{ Adjusted } \\
\hline & & $\mathrm{n}=174$ & & $\begin{array}{l}\mathrm{B} / \mathrm{OR}(95 \% \\
\mathrm{Cl})\end{array}$ & $\mathrm{p}$ & $\begin{array}{l}\mathrm{B} / \mathrm{OR}(95 \% \\
\mathrm{Cl})\end{array}$ & $\mathrm{p}$ \\
\hline $\begin{array}{l}\text { Gestational } \\
\text { age, wk }\end{array}$ & $\begin{array}{l}35.69 \pm \\
2.83\end{array}$ & $\begin{array}{l}36.02 \pm \\
3.04\end{array}$ & 0.379 & $\begin{array}{l}0.32(-0.40 \text { to } \\
1.04)\end{array}$ & 0.379 & $\begin{array}{l}-0.09(-0.47 \\
\text { to } 0.28)\end{array}$ & 0.63 \\
\hline Birth weight,g & $\begin{array}{l}2771.94 \\
\pm 524.72\end{array}$ & $\begin{array}{l}2785.15 \\
\pm 609.90\end{array}$ & 0.847 & $\begin{array}{l}13.21(-121.54 \\
\text { to } 747.96)\end{array}$ & 0.847 & $\begin{array}{l}11.96(-70.43 \\
\text { to } 106.35)\end{array}$ & 0.69 \\
\hline $\begin{array}{l}\text { Premature birth } \\
(<37 \text { weeks), N } \\
(\%)\end{array}$ & $47(43.52)$ & $97(55.75)$ & 0.046 & $\begin{array}{l}0.94(0.86 \text { to } \\
1.05)\end{array}$ & 0.293 & $\begin{array}{l}2.39(0.60 \text { to } \\
1.05)\end{array}$ & 0.99 \\
\hline $\begin{array}{l}\text { Premature birth } \\
(<34 \text { weeks), N } \\
(\%)\end{array}$ & $12(11.11)$ & $26(14.94)$ & 0.36 & $\begin{array}{l}0.94(0.82 \text { to } \\
1.08)\end{array}$ & 0.424 & $\begin{array}{l}0.84(0.57 \text { to } \\
1.13)\end{array}$ & 0.84 \\
\hline $\begin{array}{l}\text { Low birth } \\
\text { weight }(< \\
2500 \mathrm{~g}), \mathrm{N}(\%)\end{array}$ & 19(17.59) & $33(18.96)$ & 0.773 & $\begin{array}{l}0.97(0.85 \text { to } \\
1.10)\end{array}$ & 0.627 & $\begin{array}{l}0.83(0.63 \text { to } \\
1.09)\end{array}$ & 0.19 \\
\hline $\begin{array}{l}\text { Apgar score< } \\
8 \text { at } 5 \text { min,N (\%) }\end{array}$ & $13(12.04)$ & $7(4.02)$ & 0.011 & $\begin{array}{l}1.23(1.01 \text { to } \\
1.51)\end{array}$ & 0.039 & $\begin{array}{l}1.25(1.02 \text { to } \\
2.03)\end{array}$ & 0 \\
\hline $\begin{array}{l}\text { Admission to } \\
\text { NICU, N (\%) }\end{array}$ & $28(25.93)$ & $10(5.75)$ & $<.001$ & $\begin{array}{l}1.46(1.24 \text { to } \\
1.72)\end{array}$ & 0 & $\begin{array}{l}2.54(1.66 \text { to } \\
3.93)\end{array}$ & $\begin{array}{l}<.001 \\
0.001\end{array}$ \\
\hline $\begin{array}{l}\text { Assisted } \\
\text { ventilation, } \mathrm{N}\end{array}$ & 21(19.44) & $3(1.72)$ & $<.001$ & $\begin{array}{l}1.78(1.39 \text { to } \\
2.26)\end{array}$ & 0 & $\begin{array}{l}3.12(1.31 \text { to } \\
4.69)\end{array}$ & 0.03 \\
\hline
\end{tabular}

$(\%)$

Abbreviations: OR: odds ratios; $\mathrm{Cl}$ : Confidence interval;NICU,neontatal intensive care unit,MDA,Malondialdehyde.

The model was adjusted for maternal age,gravidity,parity, BMI, Hemoglobin,cholesterol,HDL,LDL,Hcy level at early term delivery,Hcy level at second trimester,

Hcy level at delivery, cord blood Hcy level,and Complications of pregnancy, Anodyne labor, Labor time,Cesarean section,Postpartum hemorrhage, and Turbid amniotic fluid. 


\section{Tabel 4 Linear or binomial logistic regression models predicting effect of ROS concentration on birth outcomes before and after adjustment for}

confounding factors.values are linear regression coefficients or logistic regression odds ratios with $95 \%$ confidence intervals.

\begin{tabular}{|c|c|c|c|c|c|c|c|}
\hline \multirow[t]{2}{*}{ variables } & \multirow{2}{*}{$\begin{array}{l}\text { High ROS } \\
n=239\end{array}$} & \multicolumn{2}{|l|}{ Low ROS } & \multicolumn{2}{|l|}{ Unadjusted } & \multicolumn{2}{|l|}{ Adjusted } \\
\hline & & $n=43$ & $\mathrm{p}$ & $\mathrm{B} / \mathrm{OR}(95 \% \mathrm{Cl})$ & $\mathrm{p}$ & B/OR (95\% Cl) & $\mathrm{p}$ \\
\hline $\begin{array}{l}\text { Gestational } \\
\text { age, wk }\end{array}$ & $\begin{array}{l}35.79 \pm \\
2.97\end{array}$ & $\begin{array}{l}36.05 \pm \\
2.99\end{array}$ & 0.663 & $\begin{array}{l}-0.26(-1.40 \text { to } \\
0.89)\end{array}$ & 0.663 & $\begin{array}{l}-0.26(-1.31 \text { to } \\
0.79)\end{array}$ & 0.63 \\
\hline $\begin{array}{l}\text { Birth } \\
\text { weight,g }\end{array}$ & $\begin{array}{l}2774.83 \pm \\
566.94\end{array}$ & $\begin{array}{l}2795.99 \\
\pm 479.40\end{array}$ & 0.848 & $\begin{array}{l}-21.06(-236.72 \\
\text { to } 194.59)\end{array}$ & 0.695 & $\begin{array}{l}-39.41(-237.23 \\
\text { to } 157.29)\end{array}$ & 0.85 \\
\hline $\begin{array}{l}\text { Premature } \\
\text { birth (<37 } \\
\text { weeks), N }\end{array}$ & $128(53.60)$ & $16(37.21)$ & 0.002 & $\begin{array}{l}1.05(0.95 \text { to } \\
1.17)\end{array}$ & 0.197 & $\begin{array}{l}1.26(0.92 \text { to } \\
1.75)\end{array}$ & 0.23 \\
\hline
\end{tabular}

$(\%)$

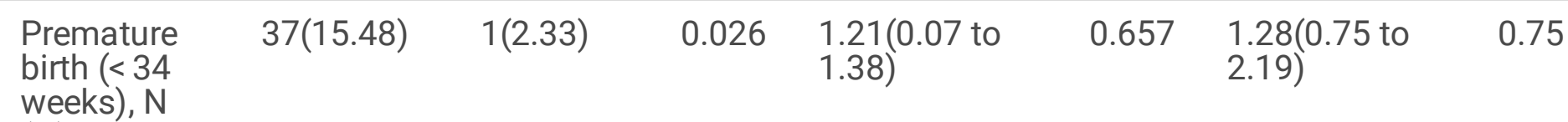

$(\%)$

\begin{tabular}{|c|c|c|c|c|c|c|}
\hline $\begin{array}{l}\text { Low birth } \\
\text { weight }(<\end{array}$ & 40(16.74) & $2(4.65)$ & 0.04 & $\begin{array}{l}1.61(0.91 \text { to } \\
1.48)\end{array}$ & 0.678 & $\begin{array}{l}1.24(0.78 \text { to } \\
2.01)\end{array}$ \\
\hline
\end{tabular}
$2500 \mathrm{~g}), \mathrm{N}$

$(\%)$

\begin{tabular}{|c|c|c|c|c|c|c|c|}
\hline $\begin{array}{l}\text { Apgar score } \\
<8 \text { at } \\
5 \text { min,N (\%) }\end{array}$ & $20(8.39)$ & $0(0.00)$ & 0.032 & $\begin{array}{l}1.79(1.422 \text { to } \\
2.25)\end{array}$ & $<$ & $\begin{array}{l}1.69(1.21 \text { to } \\
2.36)\end{array}$ & $\begin{array}{l}<.001 \\
0.00\end{array}$ \\
\hline $\begin{array}{l}\text { Admission } \\
\text { to NICU, N }\end{array}$ & $38(15.90)$ & $0(0.00)$ & 0.001 & $\begin{array}{l}2.13(1.71 \text { to } \\
2.64)\end{array}$ & $\begin{array}{l}< \\
0.001\end{array}$ & $\begin{array}{l}2.39(1.73 \\
\text { to3.30) }\end{array}$ & <. \\
\hline
\end{tabular}

$(\%)$

\begin{tabular}{|c|c|c|c|c|}
\hline $\begin{array}{l}\text { Assisted } \\
\text { ventilation, } N\end{array}$ & $24(10.04)$ & $0(0.00)$ & 0.016 & $\begin{array}{l}2.41 \text { (1.80 to } \\
3.23\end{array}$ \\
\hline
\end{tabular}
$(\%)$

Abbreviations: OR: odds ratios; $\mathrm{Cl}$ : Confidence interval;NICU,neontatal intensive care unit;ROS,Reactive Oxygen Species.

The model was adjusted for maternal age,gravidity,parity, BMI, Hemoglobin,cholesterol,HDL,LDL,Hcy level at early term delivery,Hcy level at second trimester,

Hcy level at delivery, cord blood Hcy level,and Complications of pregnancy, Anodyne labor, Labor time,Cesarean section,Postpartum hemorrhage, and Turbid amniotic fluid.

\section{Figures}




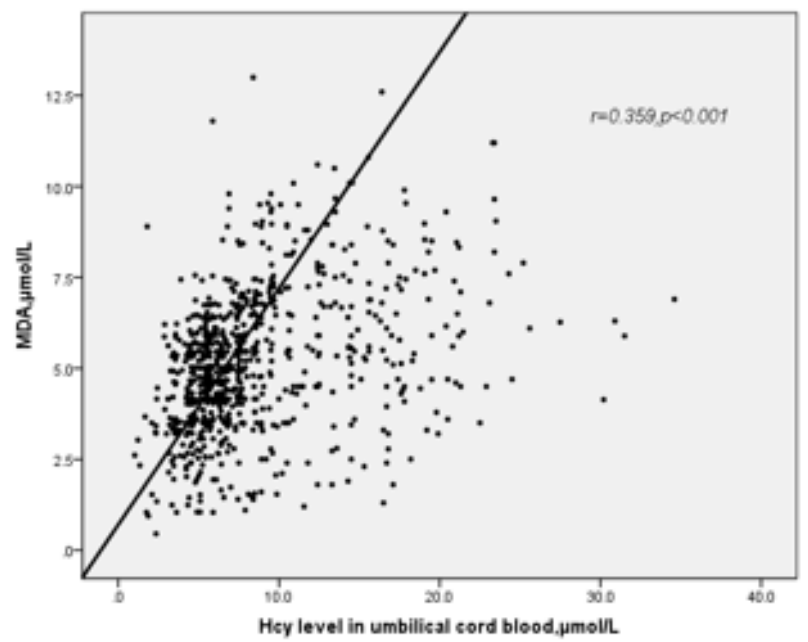

Figure 1(a). Linear correlation analysis indicated a strong positive correlation of cord blood MDA levels with cord blood Hcy.

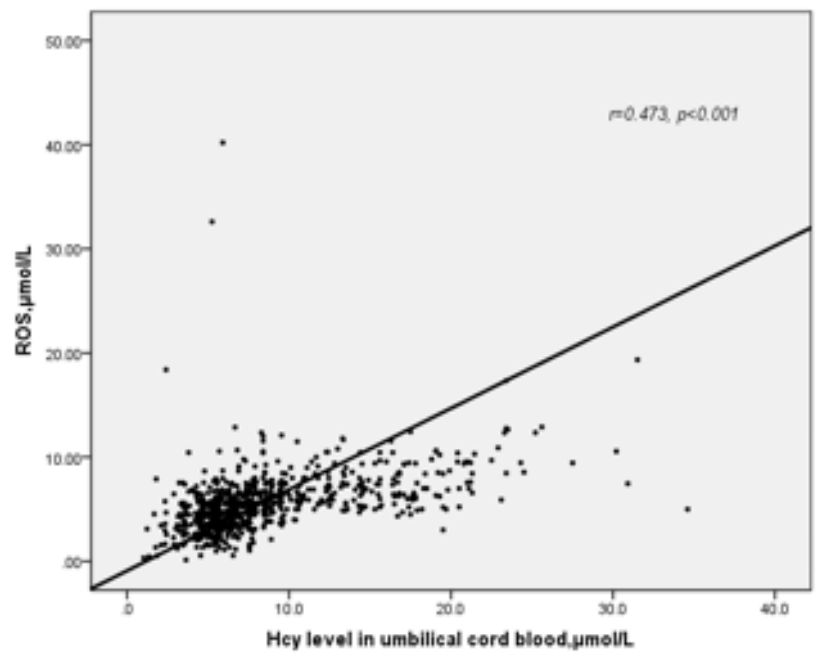

Figure $1(b)$. Linear correlation analysis indicated a strong positive correlation of cord blood ROS levels with cord blood Hcy.

\section{Figure 1}

(a). Linear correlation analysis indicated a strong positive correlation of cord blood MDA levels with cord blood Hcy. (b). Linear correlation analysis indicated a strong positive correlation of cord blood ROS levels with cord blood Hcy. 


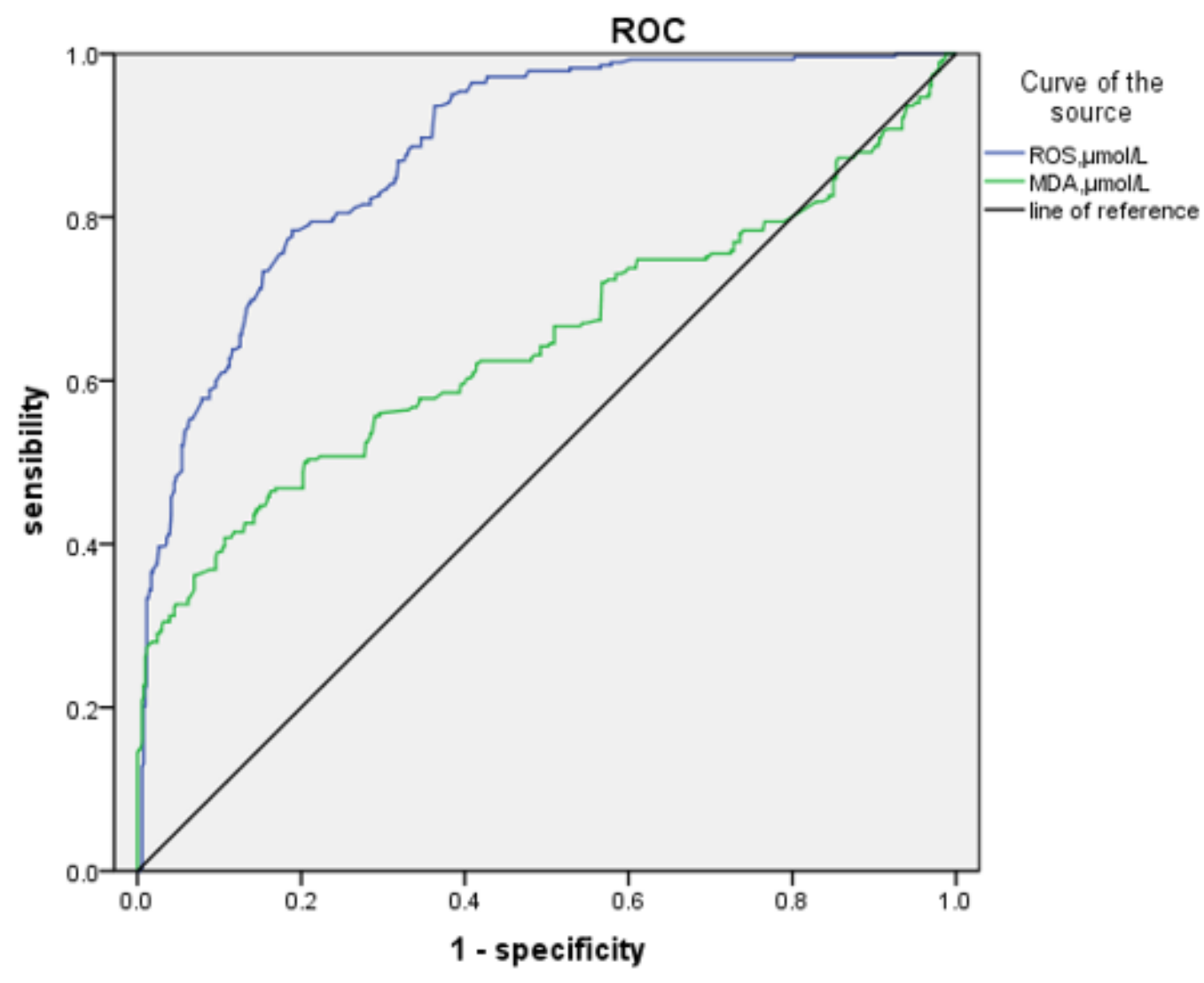

Figure 2

The ROC curve to reflect the predictive value of cord blood MDA and ROS for severe preeclampsia. 